Published in final edited form as:

Curr Allergy Asthma Rep. 2013 April ; 13(2): 171-177. doi:10.1007/s11882-013-0342-3.

\title{
Rhinitis in Older Adults
}

\author{
Sharmilee Nyenhuis ${ }^{1}$ and Sameer K. Mathur ${ }^{2,3}$ \\ ${ }^{1}$ Section of Pulmonary, Critical Care, Sleep and Allergy, University of Illinois at Chicago, Chicago, \\ IL
}

${ }^{2}$ Division of Allergy, Pulmonary and Critical Care, Department of Medicine, University of Wisconsin School of Medicine and Public Health, Madison, WI

${ }^{3}$ William S. Middleton Veterans Hospital, Madison, WI

\begin{abstract}
Rhinitis symptoms of rhinorrhea, congestion, sneezing, nasal/ocular pruritis, and postnasal drainage can significantly affect the quality of life for older adults. As the US population ages, it will be increasingly important for healthcare providers to effectively diagnose and manage rhinitis. Rhinitis is categorized broadly into allergic rhinitis and non-allergic rhinitis. Environmental changes and avoidance measures are a primary means of intervention. In addition, there are several topical therapies (nasal sprays) that can be effective for symptom control.
\end{abstract}

\section{Keywords}

Rhinitis; Older adults; Elderly; Treatment; Allergic rhinitis; Nonallergic rhinitis; Aging

\section{Introduction}

Rhinitis in its various forms can affect people of all ages and significantly affect quality of life. In adults, it is recognized as a contributor to days off work, decreased productivity, and significant expense in additional healthcare expenditures. ${ }^{1}$ Although these data are not examined separately in older adults, it is expected that symptoms are similarly debilitating and costly. Nevertheless, rhinitis is often not adequately addressed in the healthcare setting as it does not represent a life-threatening condition and especially in the older population, there are often other health issues that take precedence. However, an appropriate evaluation and management of rhinitis in older adults can significantly enhance quality of life.

In a recent study by Colas et al., validated tools to assess allergic rhinitis and sleep quality were used to demonstrate the rhinitis contribution to poor sleep quality. ${ }^{2}$ There is also increased fatigue and social burden including embarrassment, inconvenience of carrying tissues, rubbing eyes, and blowing one's nose that all contribute to diminished quality of life. ${ }^{3}$ Furthermore, rhinitis is recognized as a significant risk factor for development of frequent or chronic sinus infections. Whether the effects of rhinitis on quality of life are different in older adults has not been examined.

Correspondence: Sameer K. Mathur, MD, PhD, Assistant Professor, Division of Allergy, Pulmonary and Critical Care, Department of Medicine, University of Wisconsin School of Medicine and Public Health, H4/618 CSC, MC 9988, 600 Highland Avenue, Madison, WI 53792,sm4@medicine.wisc.edu.

Disclosure Dr. Nyenhuis has had travel/accommodations expenses covered/reimbursed by the American Thoracic Society.

Dr. Mathur has served as a consultant for Teva Pharmaceuticals. 
The US and global population is getting older, with the age group of over 65 expected to double in the US by 2030 based on US Census estimates. Therefore, understanding the management of all diseases in an older population will become increasingly important. The burden of rhinitis in the US is estimated between $10-30 \%$ of adults. The causes of rhinitis can differ in younger versus older patients; however, the evaluation and management are similar. As shown in Table 1, the diagnosis of rhinitis can be divided into two major categories of allergic rhinitis (AR) and non-allergic rhinitis (NAR), which is then subdivided into several variants. In patients above age 50, it is thought that over $60 \%$ of rhinitis is due to NAR. ${ }^{4}$ The categorization of rhinitis is important for the management of rhinitis, particularly with respect to providing guidance on avoidance measures. Otherwise, the same modalities of treatment are used for treatment rhinitis with some special considerations for use in older adults and preferred use of particular classes of medication for specific categories of rhinitis.

The same types of rhinitis that are common in other age populations are present in older adults, but with different levels of prevalence. Physiologic age-related changes occur in the nose that makes older adults more susceptible to rhinitis. These changes include an increase in cholinergic activity and mucosal gland and collagen fiber atrophy and a decrease in vascular elasticity, impaired mucociliary function and fragmentation and weakening of septal cartilage. These changes result in dryness of the mucus membranes and increased nasal congestion in older adults can contribute and exacerbate rhinitis.

\section{Allergic Rhinitis}

Allergic rhinitis (AR) is characterized by intermittent or persistent symptoms of nasal congestion, rhinorrhea, nasal/ocular pruritis, sneezing, and postnasal drainage. These symptoms are due to IgE mediated allergic inflammation in the nasal mucosa. The symptoms can exhibit a seasonal pattern with allergy to pollens or mold versus a perennial pattern with allergy to dust mite or pet dander.

The key element to the diagnosis of AR is demonstration of allergic sensitivity to allergen. This is typically done by either skin prick testing or serum testing for specific IgE to common seasonal (trees, grasses, molds, weeds) and perennial (dust mite, cockroach, pets) allergens. In older adults, it has long been recognized that total IgE levels are lower compared to younger patients. ${ }^{5}$ However, in the older adults with relatively higher levels of $\operatorname{IgE}$, there is increased atopic disease.

\section{Non-allergic Rhinitis}

Non-allergic rhinitis (NAR) is characterized by intermittent or persistent symptoms of nasal congestion, rhinorrhea, and postnasal drainage that are not the result of IgE mediated events. ${ }^{6}$ The symptoms of NAR may be perennial, persistent, intermittent, seasonal (climatic) and/or elicited by recognized triggers. These triggers include cold air, changes in climate, strong odors, pollutants, chemicals and exercise. One or more of these triggers may elicit the symptoms of NAR. Additionally, NAR may occur concurrently with allergic rhinitis in $44 \%$ to $87 \%$ of people with allergic rhinitis leading to a mixed rhinitis that has multiple triggers. ${ }^{7}$

As allergic sensitization has been shown to decrease with age, it is often thought that much of the rhinitis in older adults is non-allergic rhinitis. ${ }^{8}$ There have been very few studies that have examined the prevalence of non-allergic rhinitis in older adult populations. Jessen et al found that the prevalence of non-allergic symptoms had a U-shaped relationship with age with the lowest prevalence occurring in middle aged (50-60 y.o.) persons and an increase thereafter. ${ }^{9}$ Other studies have found little relationship with age and self-reported non- 
allergic symptoms. ${ }^{10 ; 11}$ More recently, Crawford and colleagues found that in a cohort of 134 men that there was not a decline in allergic rhinitis prevalence in older adults compared with younger adults but as others have shown that there is a decrease in allergic sensitization with age. ${ }^{12}$ Thus, allergic rhinitis remains common in older adults but nonallergic causes of rhinitis may be more prevalent with age. Further studies are necessary to determine the true prevalence of non-allergic rhinitis symptoms in older adults.

\section{Mixed Allergic and Non-allergic Rhinitis}

Many people with rhinitis have both AR and NAR, which often makes it difficult to study pure AR or NAR. ${ }^{13}$ In a study by Simola et al., which examined patients with AR at a follow up after 23 years, it was noted that skin test positivity and specific IgE levels declined. However, the changes in symptoms did not correspond to the changes in markers for allergy, which suggests that older patients may have a combination of AR and NAR contributing to symptoms. ${ }^{14}$ In 2002, the Agency for Healthcare Research and Quality (AHRQ) began to address the issue of AR versus NAR by evaluating the available evidence. The AHRQ Evidence Report found no study at that time that could distinguish these separate but overlapping conditions. ${ }^{15}$ Allergy skin testing or specific IgE testing in the blood has often been used as a determinant between allergic and non-allergic rhinitis. Though studies have shown a decline in allergen sensitivity in older adults, a robust correlation between the prevalence of allergen sensitization (skin prick test or specific $\operatorname{IgE}$ test) and allergic rhinitis exists even in older adults. Recently, Di Lorenzo and colleagues, examined over 1,000 patients with both clinical and laboratory parameters to characterize the similarities and differences between the 2 conditions. ${ }^{16}$ Overall, 10 variables were statistically different between AR and NAR. NAR subjects were older, had milder symptoms and less symptoms of sneezing, nasal pruritus and conjunctivitis, less of a clinical response to antihistamines and lower visual analog scores, peak nasal inspiratory flow and nasal eosinophils. Distinguishing between non-allergic and allergic rhinitis will help clinicians provide the most effective and appropriate treatment and help impact the morbidity associated with both diseases.

\section{Sub-types of Non-allergic Rhinitis}

Atrophic rhinitis is a type of rhinitis which is much more prevalent in older adult populations, with mean occurrence ages of 52 and 56 years, respectively. ${ }^{17}$ This type of rhinitis is manifested by symptoms of congestion, nasal crusting and fetor. Decreased blood flow to the nasal mucosa contributes to the local atrophy and leads to the enlargement of nasal space with paradoxical complaint of nasal congestion.

Vasomotor rhinitis (VMR) is manifested by rhinorrhea, congestion and less often sneezing typically after exposure to irritants including cold air and strong odors. Allergic sensitization is not a feature of VMR. The exact pathophysiology of VMR has never been established although it is thought that the rhinorrhea is caused by enhanced cholinergic glandular secretory activity and the nasal congestion due to heightened sensitivity of nociceptive neurons to stimuli. ${ }^{6}$

Non-allergic rhinitis with eosinophilia syndrome (NARES) is an inflammatory non-allergic condition and presents similarly to allergic rhinitis. The symptoms of NARES: paroxysmal exacerbations of sneezing, profuse watery rhinorrhea, nasal pruritus, nasal congestion, and occasional anosmia typically begin in the $3^{\text {rd }}$ and $4^{\text {th }}$ decades of life and may precede the development of Aspirin Exacerbated Respiratory Disease (AERD). ${ }^{18 ; 19}$ A key feature of NARES is the infiltration of eosinophils (>5\%) in nasal tissue without evidence of allergen sensitization. ${ }^{20}$ As nasal cytology is rarely performed in clinical practice today and NARES 
is responsive to typical rhinitis treatment (intranasal corticosteroids), the significance of identifying NARES in relationship with other forms of NAR is not clear.

It is important, especially in the older adult, to examine for comorbidities that may cause or contribute to rhinitis. The differential is varied from granulomatous diseases such as Wegner's granulomatosis and sarcoidosis to nasal polyposis, hypothyroidism, cerebrospinal fluid leak and side effects from medications. Medications that are known to cause rhinitis symptoms are widely used in an older adult population and range from anti-hypertensives, psychotropics, alpha-adrenergic antagonists and phosphodiesterase-5 inhibitors (See Table 2). If a patient presents with unilateral nasal symptoms, it is important to consider a nasopharyngeal neoplasm. Thus the diagnosis of NAR should be one of exclusion after other diagnoses have been ruled out.

\section{Treatment of Rhinitis}

The same medications are used for treatment of AR and NAR in older adults (Table 3). Evidence-based guidance for the treatment of NAR in older adults is lacking as NAR has been less extensively studied compared to its' more common counterpart, allergic rhinitis. The treatment of NAR typically includes the use of intranasal steroids (INSs), topical antihistamines, intranasal anti-cholinergics, oral decongestants and nasal lavage. Specific types of NAR may require unique regimen. For example, the treatment of atrophic rhinitis is focused on instituting a regimen of nasal hygiene, with nasal lavage and crust debridement, and the use of topical and/or systemic antibiotics upon the onset of purulent nasal secretions or an acute infection. ${ }^{17}$ INSs are recommended for long-term therapy in NAR. It has shown to improve the symptoms of nasal congestion compared to intranasal anti-cholinergics (ie. ipratropium bromide) in randomized controlled trials. ${ }^{15}$ Due to the wide availability of oral antihistamines now, many patients with rhinitis symptoms have tried an oral antihistamine at some point during their course of treatment. As the mechanisms of NAR typically do not involve histamine release it is intuitive to believe that antihistamines have little impact on NAR. There has been no randomized controlled study which has examined the use of antihistamines alone in the treatment of NAR. ${ }^{15}$ One study from 1982, used a firstgeneration antihistamine in combination with a decongestant and found an improvement in NAR symptoms with this regimen. ${ }^{21}$ While the first-generation antihistamines do carry some anti-cholinergic properties, which might improve rhinorrhea, it is likely the decongestant providing more benefit especially with the symptom of congestion. Secondgeneration antihistamines carry no anti-cholinergic properties, thus no benefit for NAR is anticipated. Interestingly, the topical antihistamines have been shown to be effective in NAR possibly due to the anti-inflammatory and neuroinflammatory blockade properties that azelastine and olopatadine carry. ${ }^{20}$ Studies that have compared topical antihistamines (azelastine, olopatadine) to INSs (fluticasone) have found no superiority of either drug in the treatment of NAR. ${ }^{22 ; 23}$ Furthermore, when topical antihistamines and INSs have been used concurrently, patients obtained greater symptomatic relief than with the use of either drug alone. ${ }^{24-26}$ Although oral decongestants are effective in treating congestion, few studies have examined the use of oral decongestants for the treatment of NAR. Two randomized controlled studies using phenylpropanolamine found a decrease in nasal congestion and rhinorrhea though this drug has since been removed from the market. ${ }^{15}$ No studies using pseudoephedrine in NAR have been reported. Anticholinergics such as ipratroprium bromide have demonstrated efficacy in reducing rhinorrhea in several randomized controlled trials. ${ }^{15}$ Despite its' potent effect on rhinorrhea, it has little effect on the symptom of nasal congestion. This class of medications is best used when the main rhinitis symptom is rhinorrhea as in vasomotor rhinitis. Moreover, despite the lack of an allergic component in non-allergic rhinitis, environmental controls should be discussed and targeted at irritant triggers such as tobacco smoke, strong odors, and extremes in temperature and humidity. 


\section{Special Considerations of Treatment in Older Adults}

The selection of medications for the treatment of NAR should take into account that older adults may be more susceptible to adverse effects of many of these medications. Though oral antihistamines are not typically effective in NAR, they are often used due to their wide availability. Adverse effects of first generation antihistamines include urinary retention, dry mouth, constipation, arrhythmias and postural hypertension, all of which tend to be more prevalent in older adults. Fortunately, it appears that topical antihistamines are better tolerated than the oral antihistamines. The sympathomimetic effects of oral decongestants are of concern in the presence of comorbidities that are known to be more common in older adults. Intranasal corticosteroids seem to have favorable safety and efficacy profiles in older individuals with allergic rhinitis, similar to their younger counterparts. Anticholinergics may cause excessive nasal drying and caution should be taken in patients with benign prostatic hypertrophy and narrow-angle glaucoma. At each encounter, the following should be considered especially in the older adult population: review all the current to assess for any drug interactions, examine the technique of nasal instillation and provide written treatment plans as memory may be an issue.

\section{Future Directions}

There are several recent areas of research interest in rhinitis which may be relevant for rhinitis in older adults. For example, there are data demonstrating an altered microbiome in patients with chronic rhinosinusitis compared to control patients. ${ }^{27}$ Alterations in local microbiome diversity are also related to presence of allergic disease. ${ }^{28}$ Whether there are age-related changes in microbiome diversity in the nose/sinuses and the impact on clinical symptoms of rhinitis or development of acute or chronic sinusitis are not known.

There have been several recently described inflammatory pathways involving epithelial cells, including cytokine production (IL-25, IL-33, and thymic stromal lymphopoietin), that have been associated with allergic inflammation. ${ }^{29}$ Whether these responses are equally potent and equally responsive to traditional therapies in older adults is not known.

There are data to suggest that patients may have localized production of $\operatorname{IgE}$ (also known as entopy) leading to allergic inflammation specific in the nose without evidence of allergic sensitivity assessed by conventional testing. ${ }^{30}$ Whether the decline in allergic sensitization in older adults represents a conversion of allergic responses to a more localized process is not known. For example, it is possible that some of the high prevalence of NAR is actually localized AR.

\section{Conclusions}

There remain significant gaps in our knowledge of AR and NAR in older adults ranging from the pathophysiology to the prevalence to effective treatments. With the rise in numbers of older adults in the US population, the prevalence of rhinitis is projected to increase and thus it is imperative to raise awareness of these conditions to facilitate the diagnosis and appropriate management to minimize the impact it has on the quality of life of individuals suffering with rhinitis.

\section{Acknowledgments}

Dr. Mathur has received research grant support from the National Institutes of Health. Dr. Mathur has also served as chair of the AAAAI Asthma and Allergic Diseases in the Elderly Committee and as secretary/treasurer of the Wisconsin Allergy Society. 


\section{References}

1. Bhattacharyya N. Incremental healthcare utilization and expenditures for allergic rhinitis in the United States. Laryngoscope. 2011; 121:1830-1833. [PubMed: 21997726]

2. Colas C, Galera H, Anibarro B, Soler R, Navarro A, Jauregui I, Pelaez A. Disease severity impairs sleep quality in allergic rhinitis (The SOMNIAAR study). Clin Exp Allergy. 2012; 42:1080-1087. [PubMed: 22251258]

3. Nathan RA. The burden of allergic rhinitis. Allergy Asthma Proc. 2007; 28:3-9. [PubMed: 17390749]

4. Sanico A, Togias A. Noninfectious, nonallergic rhinitis (NINAR): considerations on possible mechanisms. Am J Rhinol. 1998; 12:65-72. [PubMed: 9513662]

5. Hanneuse Y, Delespesse G, Hudson D, De Halleux F, Jacques JM. Influence of Aging on IgEMediated Reactions in Allergic Patients. Clinical Allergy. 1978; 8:165-174. [PubMed: 417878]

6. Dykewicz MS, Fineman S, Skoner DP, Nicklas R, Lee R, Blessing-Moore J, Li JT, Bernstein IL, Berger W, Spector S, Schuller D. Diagnosis and management of rhinitis: complete guidelines of the Joint Task Force on Practice Parameters in Allergy, Asthma and Immunology. American Academy of Allergy, Asthma, and Immunology. Ann Allergy Asthma Immunol. 1998; 81:478-518. [PubMed: 9860027]

7. Settipane RA. Other causes of rhinitis: mixed rhinitis, rhinitis medicamentosa, hormonal rhinitis, rhinitis of the elderly, and gustatory rhinitis. Immunol Allergy Clin North Am. 2011; 31:457-467. [PubMed: 21737037]

8*. Warm K, Backman H, Lindberg A, Lundback B, Ronmark E. Low incidence and high remission of allergic sensitization among adults. J Allergy Clin Immunol. 2012; 129:136-142. This paper provides evidence that aging results in remission of allergic sensitivity. This is in contrast to the theories that differences in allergic sensitization in older versus younger patients are due to cohort effects. [PubMed: 21975174]

9. Jessen M, Janzon L. Prevalence of non-allergic nasal complaints in an urban and a rural population in Sweden. Allergy. 1989; 44:582-587. [PubMed: 2610331]

10. Olsson P, Berglind N, Bellander T, Stjarne P. Prevalence of self-reported allergic and non-allergic rhinitis symptoms in Stockholm: relation to age, gender, olfactory sense and smoking. Acta Otolaryngol. 2003; 123:75-80. [PubMed: 12625578]

11. Settipane GA, Klein DE. Non allergic rhinitis: demography of eosinophils in nasal smear, blood total eosinophil counts and IgE levels. N Engl Reg Allergy Proc. 1985; 6:363-366. [PubMed: 3870504]

12. Crawford WW V, Gowda C, Klaustermeyer WB. Age effects on objective measures of atopy in adult asthma and rhinitis. Allergy and Asthma Proceedings. 2004; 25:175-179. [PubMed: 15317322]

13. Settipane RA, Charnock DR. Epidemiology of rhinitis: allergic and nonallergic. Clin Allergy Immunol. 2007; 19:23-34. [PubMed: 17153005]

14. Simola M, Holopainene E, Malmberg H. Changes in skin and nasal sensitivity to allergens and the course of rhinitis; a long-term follow-up study. Ann Allergy Asthma Immunol. 1999; 82:152-156. [PubMed: 10071517]

15. Long, A.; McFadden, C.; DeVine, D.; Chew, P.; Kupelnick, B.; Lau, J. Management of Allergic and Nonallergic Rhinitis. Rockville (MD): Agency for Healthcare Research and Quality (US); 2002. Evidence Reports/Technology Assessments

16. Di Lorenzo G, Pacor ML, Amodio E, Leto-Barone MS, La Piana S, D’Alcamo A, Ditta V, Martinelli N, Di Bona D. Differences and similarities between allergic and nonallergic rhinitis in a large sample of adult patients with rhinitis symptoms. Int Arch Allergy Immunol. 2011; 155:263270. [PubMed: 21293145]

17. Moore EJ, Kern EB. Atrophic rhinitis: a review of 242 cases. Am J Rhinol. 2001; 15:355-361. [PubMed: 11777241]

18. Moneret-Vautrin DA, Hsieh V, Wayoff M, Guyot JL, Mouton C, Maria Y. Nonallergic rhinitis with eosinophilia syndrome a precursor of the triad: nasal polyposis, intrinsic asthma, and intolerance to aspirin. Ann Allergy. 1990; 64:513-518. [PubMed: 2346237] 
19. Kramer MF, de la CR, Fintelmann R, Rasp G. NARES: a risk factor for obstructive sleep apnea? Am J Otolaryngol. 2004; 25:173-177. [PubMed: 15124166]

20. Kaliner MA. Nonallergic rhinopathy (formerly known as vasomotor rhinitis). Immunol Allergy Clin North Am. 2011; 31:441-455. [PubMed: 21737036]

21. Broms P, Malm L. Oral vasoconstrictors in perennial non-allergic rhinitis. Allergy. 1982; 37:6774. [PubMed: 7137522]

22. Kaliner MA. Azelastine and olopatadine in the treatment of allergic rhinitis. Ann Allergy Asthma Immunol. 2009; 103:373-380. [PubMed: 19927534]

23. Kaliner MA, Storms W, Tilles S, Spector S, Tan R, LaForce C, Lanier BQ, Chipps B. Comparison of olopatadine $0.6 \%$ nasal spray versus fluticasone propionate 50 microg in the treatment of seasonal allergic rhinitis. Allergy Asthma Proc. 2009; 30:255-262. [PubMed: 19549426]

24. Ratner PH, Hampel F, van Bavel J, Amar NJ, Daftary P, Wheeler W, Sacks H. Combination therapy with azelastine hydrochloride nasal spray and fluticasone propionate nasal spray in the treatment of patients with seasonal allergic hinitis. Ann Allergy Asthma Immunol. 2008; 100:7481. [PubMed: 18254486]

25. Hampel F, Ratner P, Haeusler JM. Safety and tolerability of levocetirizine dihydrochloride in infants and children with allergic rhinitis or chronic urticaria. Allergy Asthma Proc. 2010; 31:290295. [PubMed: 20819318]

26. LaForce CF, Carr W, Tilles SA, Chipps BE, Storms W, Meltzer EO, Edwards M. Evaluation of olopatadine hydrochloride nasal spray, $0.6 \%$, used in combination with an intranasal corticosteroid in seasonal allergic rhinitis. Allergy Asthma Proc. 2010; 31:132-140. [PubMed: 20302683]

27**. Feazel LM, Robertson CE, Ramakrishnan VR, Frank DN. Microbiome complexity and Staphylococcus aureus in chronic rhinosinusitis. Laryngoscope. 2012; 122:467-472. This paper describes a novel concept of colonized microbes contributing to the inflammatory status in the nasal cavity. Future studies will be needed to address whether modifying the nasal microbiome can impact symptoms of rhinitis. [PubMed: 22253013]

28. Hanski I, von Hertzen L, Fyhrquist N, Koskinen K, Torppa K, Laatikainen T, Karisola P, Auvinen P, Paulin L, Makela MJ, Vartiainen E, Kosunen TU, Alenius H, Haahtela T. Environmental biodiversity, human microbiota, and allergy are interrelated. Proc Natl Acad Sci US A. 2012; 109:8334-8339.

29. Broide DH. Allergic rhinitis: Pathophysiology. Allergy Asthma Proc. 2010; 31:370-374. [PubMed: 20929602]

30**. Rondon C, Campo P, Galindo L, Blanca-Lopez N, Cassinello MS, Rodriguez-Bada JL, Torres MJ, Blanca M. Prevalence and clinical relevance of local allergic rhinitis. Allergy. 2012; 67:1282-1288. This paper highlights a growing body of evidence suggesting rhinitis symptoms can be due to a localized allergic sensitivity. Recognition of the localized allergic sensitivity or entopy will likely lead to new diagnostic techniques and new therapeutic options. [PubMed: 22913574] 


\title{
Table 1
}

\section{Categorization of Rhinitis}

\author{
Allergic Rhinitis \\ Non-allergic Rhinitis \\ Atrophic Rhinitis \\ Vasomotor Rhinitis \\ Non-allergic Rhinitis with Eosinophilia (NARES) \\ Gustatory Rhinitis \\ Drug-Induced Rhinitis
}


Table 2

Medications that can cause or contribute to rhinitis

\begin{tabular}{|ll|}
\hline - & ASA/NSAIDs \\
- & Alpha blockers (doxazosin, terazosin) \\
- & Beta-blockers (carvedilol, labetalol, nadolol) \\
- & Calcium channel blockers \\
- & Diuretics \\
- & Oxymetolazone \\
- & Oral contraceptives \\
- & Phosphodiesterase 5 inhibitors (sildenafil, tadalafil, vardanafil) \\
- & Psychotropics (risperidone, chlorpromazine, amitriptyline) \\
- & Phentolamine \\
\hline
\end{tabular}

(Adapted from Dykewicz et al. [6].) 
Table 3

Medications for treatment of rhinitis

\begin{tabular}{|c|c|c|c|}
\hline Medication class & Generic drug (Trade name) & Dose & Therapeutic considerations \\
\hline \multicolumn{4}{|l|}{ Corticosteroids } \\
\hline Oral & Prednisone or methylprednisolone & variable & $\begin{array}{l}\text { Short course ( } 5-7 \text { days) may be appropriate } \\
\text { for severe nasal symptoms }\end{array}$ \\
\hline \multirow[t]{9}{*}{ Intranasal } & $\begin{array}{l}\text { Beclomethasone monohydrate } \\
\text { (Beconase AQ) }\end{array}$ & $1-2$ sp nos bid & \multirow{9}{*}{$\begin{array}{l}\text { Side effects include nasal burning, dryness } \\
\text { and epistaxis } \\
\text { Without significant systemic SE in adults } \\
\text { though monitoring for glaucoma } \\
\text { recommended especially if patient is also } \\
\text { taking corticosteroids for other chronic } \\
\text { diseases. }\end{array}$} \\
\hline & Fluticasone propionate (Flonase) & 2 sp nos qdaily & \\
\hline & Flunisolide (Nasarel) & 2 sp nos bid-tid & \\
\hline & Triamcinolone (Nasacort AQ) & $1-2$ sp nos qdaily & \\
\hline & Mometasone (Nasonex) & 2 sp nos qdaily & \\
\hline & Budesonide (Rhinocort AQ) & $1-4$ sp nos qdaily & \\
\hline & Fluticasone furoate (Veramyst) & 2 sp nos qdaily & \\
\hline & Ciclesonide (Omnaris) & $2 \mathrm{sp}$ nos qdaily & \\
\hline & Ciclesonide (Zetonna) & 1 sp nos qdaily & \\
\hline \multicolumn{4}{|l|}{ Antihistamines } \\
\hline \multirow{12}{*}{$\begin{array}{l}\text { Oral } \\
1^{\text {st }} \text { generation } \\
2^{\text {nd }} \text { generation }\end{array}$} & Diphenyhydramine & $25-50 \mathrm{mg}$ qid & \multirow{6}{*}{$\begin{array}{l}\text { Side effects: sedation, dizziness, reduced } \\
\text { mental alertness and confusion, urinary } \\
\text { retention, constipation, arrhythmias and } \\
\text { postural hypotension }\end{array}$} \\
\hline & Cyproheptadine & $4 \mathrm{mg}$ tid & \\
\hline & Hydroxyzine & $25 \mathrm{mg}$ qid & \\
\hline & Chlorphenerimine & $4 \mathrm{mg}$ qid & \\
\hline & Promethazine & $25 \mathrm{mg}$ qid & \\
\hline & Clemastine & 1.34 mg bid- tid & \\
\hline & Loratadine & $10 \mathrm{mg}$ qdaily & \multirow{6}{*}{$\begin{array}{l}\text { Preferred over } 1^{\text {st }} \text { generation due to less } \\
\text { sedation, performance impairment and } \\
\text { anticholinergic effects }\end{array}$} \\
\hline & Desloratadine & 5 mg qdaily & \\
\hline & Cetirizine & $5-10 \mathrm{mg}$ qdaily & \\
\hline & Levocetirizine & 5 mg qdaily & \\
\hline & Fexofenadine & $\begin{array}{l}180 \mathrm{mg} \text { qdaily or } \\
60 \mathrm{mg} \text { bid }\end{array}$ & \\
\hline & Acrivastine & $8 \mathrm{mg}$ qid & \\
\hline \multirow[t]{2}{*}{ Intranasal } & Azelastine (Astelin, Astepro) & 2 sp nos bid & \multirow{2}{*}{$\begin{array}{l}\text { Minimal side effects: possible sedation, bitter } \\
\text { taste }\end{array}$} \\
\hline & Olopatadine (Patanase) & 2 sp nos bid & \\
\hline $\begin{array}{l}\text { Corticosteroid +Antihistamine } \\
\text { Intranasal }\end{array}$ & Fluticasone +Azelastine (Dymista) & 1 sp nos bid & $\begin{array}{l}\text { Minimal side effects: possible sedation, bitter } \\
\text { taste }\end{array}$ \\
\hline $\begin{array}{l}\text { Anti-cholinergics } \\
\text { Intranasal }\end{array}$ & Ipratropium bromide (Atrovent) & 2 sp nos bid-tid & Side effects: epistasis, nasal dryness \\
\hline \multirow[t]{3}{*}{$\begin{array}{l}\text { Leukotriene modifying agents } \\
\text { Oral }\end{array}$} & Zileuton (Zyflo) & $\begin{array}{l}600 \mathrm{mg} \text { qid or } \\
1200 \mathrm{mg} \text { CR bid }\end{array}$ & \multirow{3}{*}{$\begin{array}{l}\text { Decreased clearance of zarfilukast in person > } \\
65 \text { yo Zafirlukast and zileuton are hepatically } \\
\text { metabolized and may produce liver function } \\
\text { abnormalities. } \\
\text { These } 2 \text { drugs may interfere with the } \\
\text { metabolism of other drugs commonly used in } \\
\text { the older adults, such as warfarin }\end{array}$} \\
\hline & Zarfilukast (Accolate) & $20 \mathrm{mg}$ bid & \\
\hline & Montelukast (Singulair) & $10 \mathrm{mg}$ qdaily & \\
\hline \multicolumn{4}{|l|}{ Decongestants } \\
\hline Oral & Pseudoephedrine & $\begin{array}{l}30-60 \mathrm{mg} \mathrm{q} 4-6 \mathrm{~h} \\
\text { or } 120 \mathrm{mg} \mathrm{q} 12 \mathrm{~h}\end{array}$ & $\begin{array}{l}\text { Caution in those with a history of cardiac } \\
\text { arrhythmia, angina pectoris, cerebrovascular }\end{array}$ \\
\hline
\end{tabular}




\begin{tabular}{|c|l|l|l|}
\hline Medication class & Generic drug (Trade name) & Dose & Therapeutic considerations \\
\cline { 2 - 3 } & Phenylephrine & $10-20 \mathrm{mg} \mathrm{q} 4 \mathrm{~h}$ & $\begin{array}{l}\text { disease, hypertension, bladder neck } \\
\text { obstruction, glaucoma, or hyperthyroidism. } \\
\text { Side effects: tachycardia, dry mouth, anxiety, } \\
\text { insomnia and irritability. }\end{array}$ \\
\hline \multirow{2}{*}{ Intranasal } & Oxymetalazone & $4-6 \mathrm{sp}$ nos bid & $\begin{array}{l}\text { Rhinitis medicamentosa with prolonged use } \\
(>5 \mathrm{~d})\end{array}$ \\
\cline { 2 - 4 } & Xylometazoline & $1 \mathrm{sp}$ nos bid-tid & \\
\hline Mast Cell Stabilizer & & & $\begin{array}{l}\text { Less effective than corticosteroids and must } \\
\text { be taken for at least 1 week for detectable } \\
\text { symptom relief Minimal side effects }\end{array}$ \\
\hline Intranasal & Cromolyn sodium (NasalCrom) & $1 \mathrm{sp}$ nos q4-6h & \\
\hline
\end{tabular}

